\title{
A Concomitant Occurrence of the Atlantoaxial Sublux- ation with Rare Vertebral Formation and Segmentation Defects
}

\author{
Man Kyu Choi, Sung Bum Kim, Jun Ho Lee \\ Department of Neurosurgery, Kyung Hee University Hospital, Kyung Hee University College of Medicine, Seoul, Korea
}

An atlantoaxial subluxation from the unstable Os odontoideum by the failure of proper integrations between the embryological somites might be a commonly reported pathology. However, its suspicious origin or paralleled occurrence with other congenital anomalies of vertebral body might be a relatively rare phenomenon. The authors present two cases, who simply presented with clinical signs of prolonged, intractable cervicalgia without any neurological deficits, revealed this rare feature of $\mathrm{C} 1-2$ subluxation from the unstable, orthotropic type of Os odontoideum that coincide with congenitally fused cervical vertebral bodies between $\mathrm{C} 2-3$. Surprisingly, in one case, when traced from the lower cervical down to the thoracic-lumbar levels during the preoperative work-up process, was also compromised with multi-level butterfly vertebrae formations. Presented cases highlight the association of various congenital vertebrae anomalies and the rationale to fuse only affected joints.

Key Words : Atlanto-axial joint · Congenital anomaly · Os odontoideum · Joint instability.

\section{INTRODUCTION}

The odontoid process is a part of the $\mathrm{C} 2$ or axis vertebra and might be the central pillar that forms the crucial pivot among the consisting structures inside the craniovertebral junction ${ }^{5}$. The development of odontoid is a complex process that is already involved with four ossification centers from the birth". Due to these embryological complexity, it might be vulnerable to a variety of congenital and acquired conditions such as the occurrence of an os odontoideum with its subsequent instability by atlantoaxial dislocation (AAD).

Apart from rarity, its combination with multiple congenital formation and segmentation defects inside the vertebral column might put a demanding task over a radiologist or surgeon in the selection of a description or terminology for a proper diagnosis as well as its interpretation, and would subsequently be in dilemma in its management choice.

The authors present two case of orthotropic type Os odontoideum induced AAD combined with the congenitally fused cervical vertebrae. One of two cases was treated by $\mathrm{C} 1-\mathrm{C} 2 \mathrm{fu}-$ sion and the feasible rationale for such a combination of rare congenital formation and segmentation defects is discussed.

- Received : October 12, 2020 •Revised : December 30, 2020 •Accepted : January 27, 2021

- Address for reprints : Jun Ho Lee

Department of Neurosurgery, Kyung Hee University Hospital, Kyung Hee University College of Medicine, 23 Kyungheedae-ro, Dongdaemun-gu, Seoul 02447, Korea Tel : +82-2-958-8405, Fax : +82-2-958-8380, E-mail : m009924@khu.ac.kr, ORCID : https://orcid.org/0000-0001-6246-8053

This is an Open Access article distributed under the terms of the Creative Commons Attribution Non-Commercial License (http://creativecommons.org/licenses/by-nc/4.0) which permits unrestricted non-commercial use, distribution, and reproduction in any medium, provided the original work is properly cited. 


\section{CASE REPORT}

\section{Case 1}

This 65-year-old female presented with the clinical signs of neck pain and subjective systemic spasticity spanning over recent few years. However, the objective finding acquired during the detailed clinical examinations was limited to an intractable cervicalgia provocation only especially during the neck extension without any neurological deficits.

The initial dynamic radiographs of the cervical spine revealed the AAD instability phenomenon on neck extension, which was completely reducible during the patient's self-flexional maneuver, suggesting a flexibility for this condition (Fig. 1). The main background causing this AAD instability was found out to be the inherent existence of an orthotropic type of Os odontoideum, as revealed through the 3-dimensional reconstructed images by the computed tomography (CT). Surprisingly, as concomitantly featured inside the same frame through these CT scans, there were coexistent anomalous features of the inherently fused cervical spine between C2-3 level and inside C3-4 vertebral bodies, respectively. This congenitally fused, bony bridging was most notable along the both anterior and posterior vertebral body margins as well as between the lateral masses and spinous processes across the $\mathrm{C} 2-3$ (Fig. 2).

In a whole spinal evaluation in order to detect the other fea-

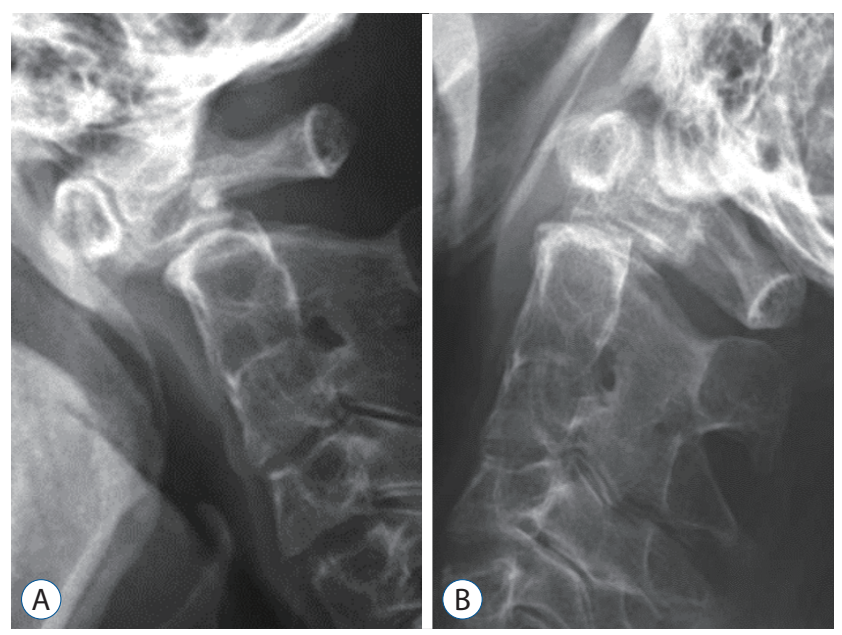

Fig. 1. The dynamic radiographies for the patient during the flexion (A) and extension (B) feature an unstable atlantoaxial dislocated condition. Note the complete reducibility for this condition during the patient's self-flexional maneuver. The congenitally fused vertebrae between C2 and C 3 with its prominent bony bridging formation between the spinous processes is also noted. sibly affected levels, she was also compromised with the multilevel butterfly vertebrae formations when traced from the lower cervical down to the thoracic-lumbar junctional levels by the CT work-up process (Fig. 3). Fortunately, none of these butterfly vertebrae infiltrated levels was affected with other pathologic or degenerative spinal conditions mandating another treatment. Also, there was no other congenital syndromes or anomalies involving the systemic organs associated.

A reduction by posterior screw fixation augmented with allografts on lay over the $\mathrm{C} 1-2$ level was schemed and performed to completely resolve the initial intractable discomfort as well as to deter further neurological deterioration for the patient by providing a solid stability at the corresponding unstable level. After this reductive operation, full radiological restoration of the AAD instability as well as the complete resolution of the original cervicalgia was achieved for the patient (Fig. 4).

\section{Case 2}

A 26-year-old female patient was referred to the outpatient department seeking for an accurate diagnosis on her cervical spinal condition after having suffered from the intractable cervicalgia as well as ensuing cervicogenic headache for over the past 3 years. Despite the clinical process had become particularly worse during the past 2 months prior to this visit, she

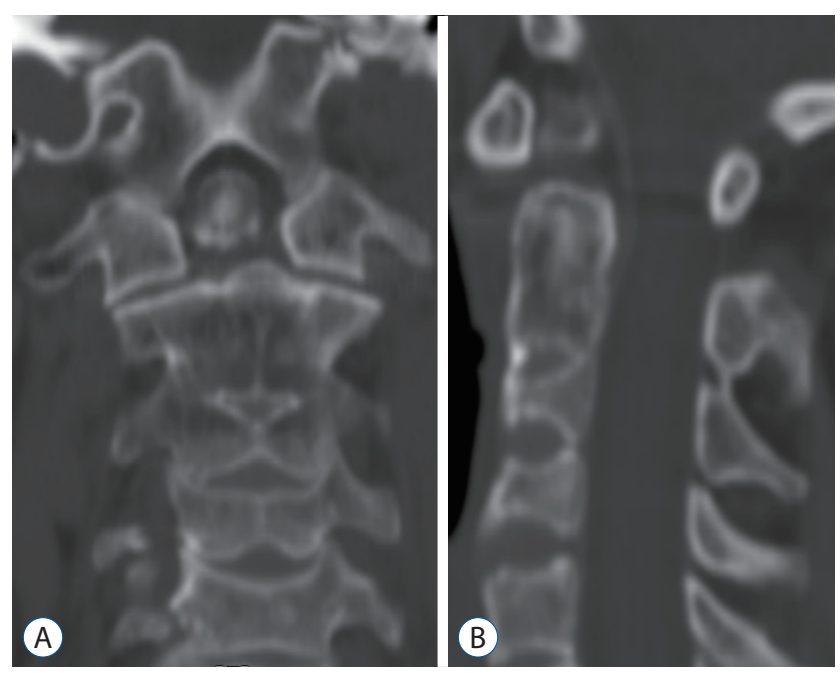

Fig. 2. The 3-dimensional reconstructed coronal (A) and sagittal (B) scans by the cervical spine computed tomography reveal an orthotopic type of Os odontoideum, margined and separated from the caudal C2 body by clean cortical bone. The fused, bony bridging phenomena are prominent along the both anterior and posterior vertebral body margins as well as between the lateral masses of the $\mathrm{C} 2, \mathrm{C} 3$, and $\mathrm{C} 4$. 
was not aware or informed of her feasible pathologic condition due to the seldom visits to the non-eligible pain clinics for the
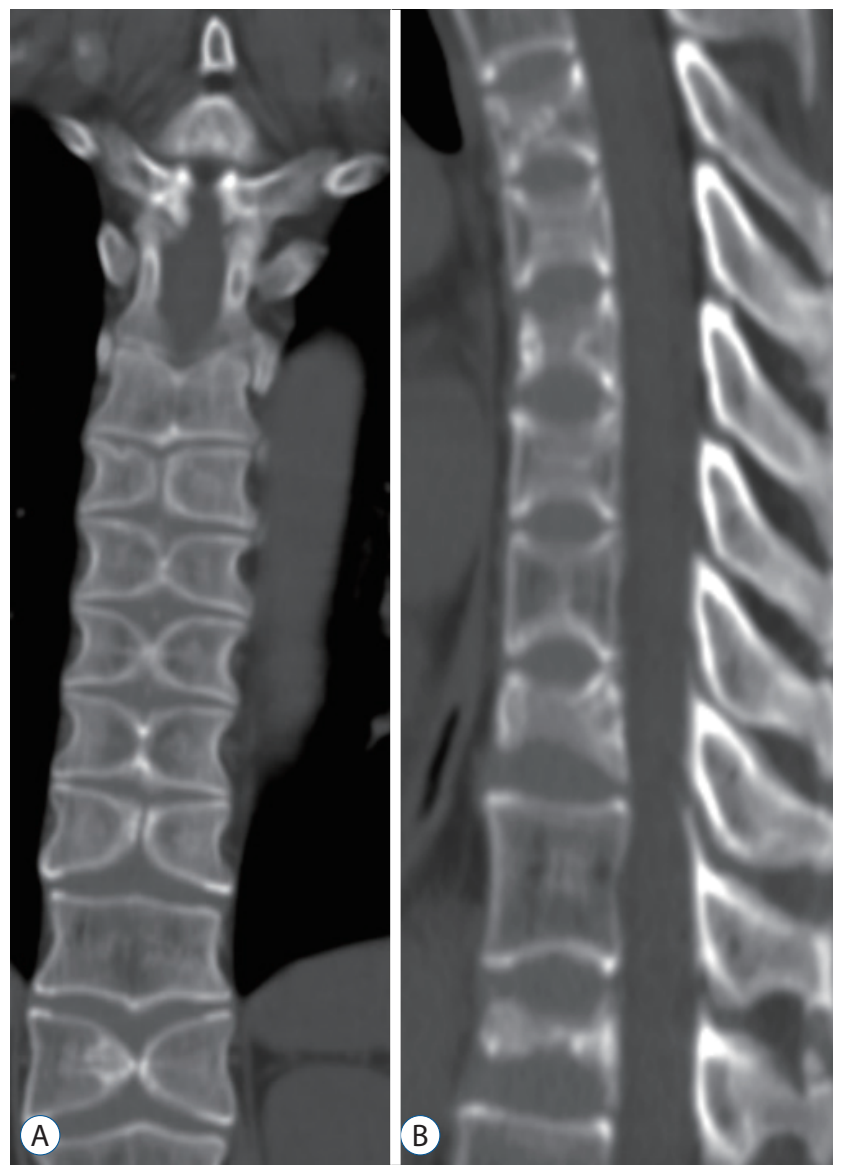

Fig. 3. The 3-dimensional reconstructed coronal (A) and sagittal (B) computed tomography scans with the inclusion of the whole vertebral levels clearly depict the extension of the multilevel butterfly vertebrae formations from the lower cervical to thoracic-lumbar junctional levels with the few intervening normal shaped vertebrae.
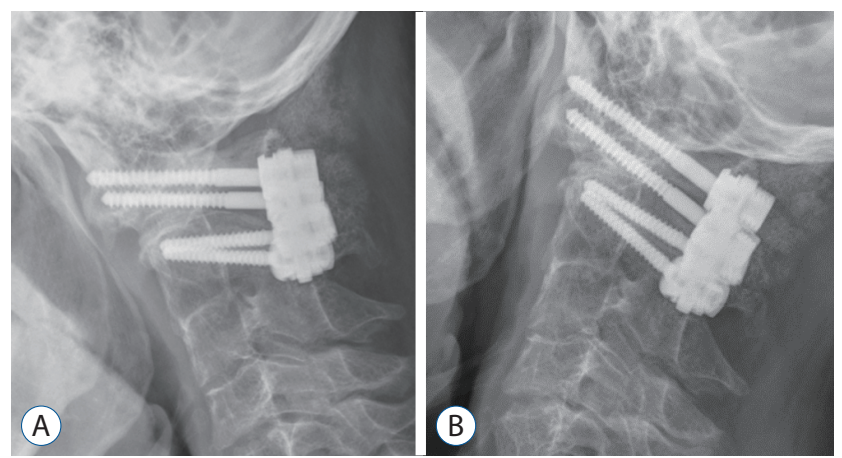

Fig. 4. The dynamic radiographs during the neck flexion $(A)$ and extension (B) taken 9 months' post-operative period after the reduction with allograft on-layed feature a full radiological restoration of the inherent atlantoaxial dislocated instability. sake of mere, temporary symptom relief during her daily career.

The lateral view among the plain radiographs of her cervical spine showed the AAD feature with slightly retropulsed Os odontoideum over C2 body proper, which was untowardly stabilized by cortical rim connection with ventral portion of the C3 vertebra (Fig. 5). She was not managed to take additional dynamic radiographs for the further verification of $\mathrm{AAD}$ phenomenon due to the exaggerated symptomatic provocation during the enforced neck extension maneuver. As differentiated from the lower subaxial cervical vertebrae, the decreased anterior-posterior (AP) diameter of the vertebral bodies are also noted at the fused C2, C3, as well as C4 levels.

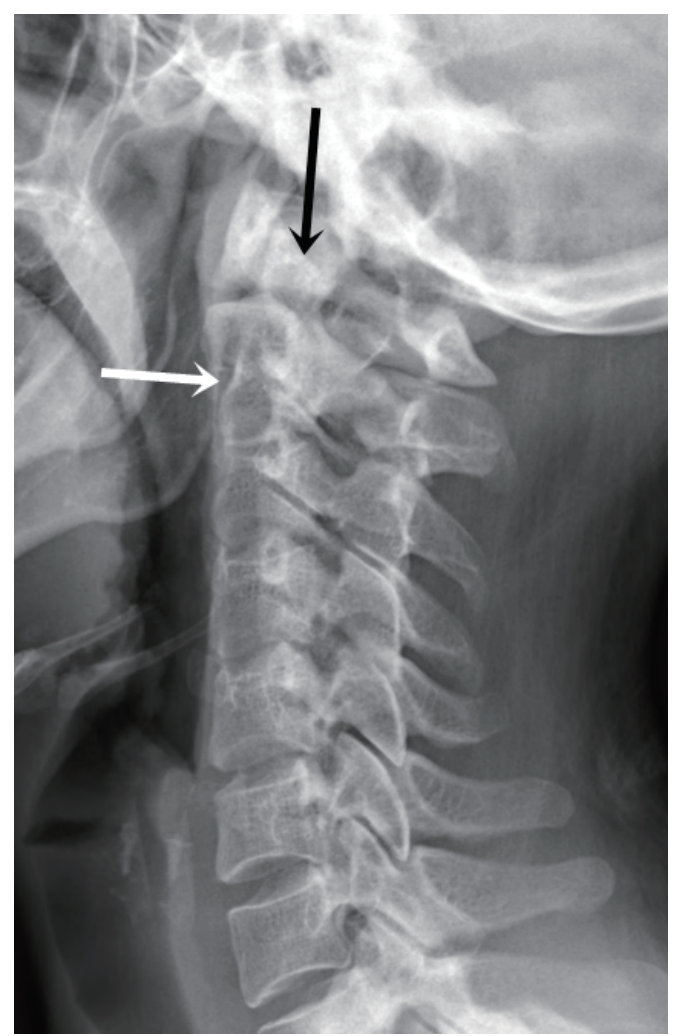

Fig. 5. The plain radiographs, lateral view of the case 2 showed the AAD feature with slightly retropulsed os odontoideum over C2 body proper (black arrow), which was untowardly stabilized by cortical rim connection with ventral portion of the C 3 vertebra (white arrow). Note the decreased anterior-posterior diameter of the vertebral bodies at the fused C2, C3, as well as C4 levels as compared with the lower subaxial cervical bodies. 


\section{DISCUSSION}

Congenital fusion of cervical vertebrae (CFCV) from the segmentation defects of cervical spine is a rare anomaly but do not have low incidence ${ }^{4,7)}$. Although this fused condition might be either congenital or acquired, the most important differentiated radiographic aspect for CFCV would be the decreased AP diameter of the vertebra, as seen in this case. Also, the individual measurements of the two vertebrae bodies' height is equal to the two fused vertebrae's height including the intervertebral disc ${ }^{18)}$. One of the proposed reason for the development of a CFCV would be a disturbance in normal spinal segmentation during embryological development, followed by a decrease in local blood supply between 3rd to 8th week of embryonic period ${ }^{14)}$. In this condition, two fused vertebrae appear structurally and functionally as one unit ${ }^{18)}$ and subsequently might result in a biochemical stress overload to the adjoining intervertebral functional unit, which could lead to a premature degenerative spondylotic change or even a graver consequence like instability problems at the adjacent segments ${ }^{13,14}$. This condition has been sporadically reported to predispose a congenital AAD development, with its preferential level would be between the facet joints of the C2 and C3, as depicted in this current case $e^{10,16,17)}$. Fused cervical vertebrae with congenital AAD is rare, but some cases have been reported (Table 1). Unlike the previous reports, the presented case is very rare in that it was occurred with thoracic butterfly vertebrae.

The presence of adjacent multilevel butterfly vertebrae complicates this combination of anomalies further. These anomalies might originate from the defects pertaining to formation (either partial or complete) and the intercalation of central ossification center or a sagittal cleft caused by the persistence of the notochord might give rise to a butterfly vertebra ${ }^{8}$. The two parts of bodies are connected by cartilage that prevents splaying $^{12)}$ and possibly transmits the body weight efficiently to the normal vertebral bodies below. Due to this efficient load transmission, they are usually asymptomatic and do not require treatment ${ }^{11)}$. Nonetheless, multiple previous reports have linked butterfly vertebrae with low back pain which might be the most common presenting complaint occurring in $23 \%$ of all cases and $30 \%$ of non-syndromic cases ${ }^{6}$. However, still, the association between butterfly vertebrae and low back pain remains unproven and might be unrelated to the structural abnormality; thus the etiology of this phenomena has not been rigorously explained.

It is important to understand the radiographic features of butterfly vertebrae since they have been frequently misdiagnosed as one of the compression fracture previously. Close examination of the adjacent vertebrae will show the features of long-standing deformity such as exaggerated elongation anterior margins to occupy the defect, and a normal intervertebral disc $^{2}$. In addition, butterfly vertebrae typically cause less kyphosis than would be expected from the significant anterior wedging ${ }^{1)}$.

According to a systematic review from Katsuura and $\mathrm{Kim}^{6}$, there was a high association between the presence of multiple butterfly vertebrae and a syndromic presentation ( $40 / 45$ cases, $89 \%)$. The associated organ system that is most frequently vulnerable would be any structural abnormality inside the vertebral column that is not affected with the butterfly vertebrae, such as scoliosis (most common), failure of formation and segmentation, block vertebrae, kyphosis, and spina bifida. However, despite pre-existing several descriptions on these findings with concomitant neurological deficits, these reports were mostly based on the clinical symptoms as opposed to structural problems, and perhaps were unrelated directly to the butterfly vertebrae ${ }^{3)}$. Therefore, the feasible hypothesis on

Table 1. List of congenital atlantoaxial instability previously reported in the literatures

\begin{tabular}{lccccc}
\hline Study & Age (years) & Sex & Fused segment & Butterfly vertebrae & Others \\
\hline Deepak et al. ${ }^{3)}(2017)$ & 14 & F & C2-3 & C3 & Absent posterior C2 \\
Shah et al. ${ }^{15)}(2018)$ & 4 & M & C2-7 & - & 1 patient; assimilation of atlas \\
& 5 & F & C2-6 or 7 & - & 3 patients; bifid anterior and posterior \\
& 14 & F & C2-7 & - & arches of the atlas \\
& 27 & F & C2-6 or 7 & - \\
\hline
\end{tabular}

$F$ : female, $M$ : male 
how these vertebrae formation and segmentation defects have been elucidated simultaneously as in this case might not be available even up to recent evidences. A consideration in terms of sclerotomes developmental anomaly that might interpret these phenomena as a whole should be pondered on by the author in the future.

\section{CONCLUSION}

The combinations of vertebrae formation and segmentation defects might coexist. However, the combination of multilevel butterfly bodies along with congenitally fused cervical vertebrae as well as AAD is a rare phenomenon. Their presences should raise suspicion for a coexisting broader congenital syndrome and should prompt the systemic diagnostic workup. However, the presence of such defects would not preclude or alter the management of AAD. Fusing the $\mathrm{C} 1-\mathrm{C} 2$ joints despite associated other complex anomalies appears to be a balanced approach as in this case.

\section{CONFLICTS OF INTEREST}

No potential conflict of interest relevant to this article was reported.

\section{INFORMED CONSENT}

Informed consent was obtained from all individual participants included in this study.

\section{AUTHOR CONTRIBUTIONS}

\section{Conceptualization : JHL}

Data curation : JHL

Formal analysis : MKC

Methodology : MKC

Project administration : SBK

Visualization : MKC

Writing - original draft : JHL

Writing - review \& editing : MKC

\section{ORCID}

$\begin{array}{ll}\text { Man Kyu Choi } & \text { https://orcid.org/0000-0001-6670-7541 } \\ \text { Sung Bum Kim } & \text { https://orcid.org/0000-0001-8447-2176 } \\ \text { Jun Ho Lee } & \text { https://orcid.org/0000-0001-6246-8053 }\end{array}$

\section{References}

1. Cave P : Butterfly vertebra. Br J Radiol 31 : 503-506, 1958

2. Colquhoun J : Butterfly vertebra or sagittal cleft vertebra. Am J Orthop Surg $10: 44-50,1968$

3. Deepak AN, Salunke P, Kamble RP : Case of atlantoaxial dislocation with assimilated C1, absent posterior C2, butterfly C3, and fused subaxial cervical spine: management dilemma with multiple segmentation and formation defects. J Pediatr Neurosci 12 : 72-74, 2017

4. Gray SW, Romaine CB, Skandalakis JE : Congenital fusion of the cervical vertebrae. Surg Gynecol Obstet 118 : 373-385, 1964

5. Jain N, Verma R, Garga UC, Baruah BP, Jain SK, Bhaskar SN : CT and MR imaging of odontoid abnormalities: a pictorial review. Indian J Radiol Imaging 26 : 108-119, 2016

6. Katsuura Y, Kim HJ : Butterfly vertebrae: a systematic review of the literature and analysis. Global Spine J 9 : 666-679, 2019

7. McRae DL, Barnum AS : Occipitalization of the atlas. Am J Roentgenol Radium Ther Nucl Med 70 : 23-46, 1953

8. Müller F, O'Rahilly R, Benson DR : The early origin of vertebral anomalies, as illustrated by a 'butterfly vertebra'. J Anat 149 : 157-169, 1986

9. Pang D, Thompson DN : Embryology and bony malformations of the craniovertebral junction. Childs Nerv Syst 27 : 523-564, 2011

10. Patcas R, Tausch D, Pandis N, Manestar M, Ullrich O, Karlo CA, et al. : IIlusions of fusions: assessing cervical vertebral fusion on lateral cephalograms, multidetector computed tomographs, and cone-beam computed tomographs. Am J Orthod Dentofacial Orthop 143 : 213-220, 2013

11. Patinharayil G, Han CW, Marthya A, Meethall KC, Surendran S, Rudrappa GH : Butterfly vertebra: an uncommon congenital spinal anomaly. Spine (Phila Pa 1976) 33 : E926-E928, 2008

12. Patra DP, Salunke P, Pramanick $G$ : Butterfly C2 vertebra: an unusual finding in a case of os odontoideum. Pediatr Neurosurg 49 : 320323,2013

13. Salunke P, Behari S, Kirankumar MV, Sharma MS, Jaiswal AK, Jain VK : Pediatric congenital atlantoaxial dislocation: differences between the irreducible and reducible varieties. J Neurosurg 104(2 Suppl) : 115122, 2006

14. Salunke P, Sharma M, Sodhi HB, Mukherjee KK, Khandelwal NK : Congenital atlantoaxial dislocation: a dynamic process and role of facets in irreducibility. J Neurosurg Spine 15 : 678-685, 2011

15. Shah A, Kaswa A, Jain S, Goel A : Atlantoaxial instability associated with pan cervical vertebral fusion: report on management of 4 cases. Neurol India 66 : 147-150, 2018

16. Smoker WR : Congenital anomalies of the cervical spine. Neuroimag- 
ing Clin N Am 5 : 427-449, 1995

17. Yang SY, Boniello AJ, Poorman CE, Chang AL, Wang S, Passias PG : A review of the diagnosis and treatment of atlantoaxial dislocations. Global Spine J 4 : 197-210, 2014
18. Yin $H F$, Yang KQ, Lou SQ : Clinical significance of congenital fusion of cervical vertebrae: a report of 87 cases. Zhonghua Wai Ke Za Zhi 27 : 75-77, 124, 1989 